\title{
AN ELECTRICAL TRAP FOR THE CONTROL OF COCKROACHES AND OTHER DOMESTIC PESTS
}

\author{
Mr. N. R. H. BURGESS, B.Sc., F.R.E.S., M.I.Biol. \\ Sergeant S. N. McDERMOTT, F.I.M.L.T., R.A.M.C. \\ Royal Army Medical College, Millbank \\ Mr. A. P. BLANCH \\ Department of the Environment
}

\begin{abstract}
SUMMARY: A 12 inch square plastic bowl some 5 inches deep with sloping ramps has three strands of $\frac{1}{2}$ inch copper tube fitted around the inside surface, the upper band about 1 inch below the rim, and each 1/16 inch apart. A low voltage of 12 to 25 volts is applied to the tapes from a mains transformer or battery. Small animals are attracted up the ramps and into the bowl by a suitable bait; as they cross the tapes they are subjected to a small electrical shock and fall into the bowl. In attempting to escape after feeding, they receive a further shock when they touch the tapes and are retained in the bowl. The catch can be killed at intervals by immersion in alcohol or by poisoning the bait.
\end{abstract}

\section{Introduction}

The eradication of many domestic pests, in particular the German cockroach Blattella germanica, entails the use of chemical insecticides and some degree of disruption of normal activities in the area being treated. This is particularly inconvenient when eradication is attempted in situations such as hospital kitchens or canteens. In addition, resistance of certain insects to insecticides is becoming a considerable problem.

The method described below is a long-term technique, which may never completely eradicate the pest, but will keep it at an acceptable and very low level of infestation without any disruption of activities or little inconvenience to the user. It requires a minimum of maintenance and is inexpensive to produce.

\section{The trap}

\section{Materials and methods}

A black plastic bowl some 12 inches square and 5 inches deep was found to be the optimum size and consistency. An electrical tape of copper foil with conducting pressure-sensitive adhesive $\frac{1}{2}$ inch wide and 3.5 thousandth of an inch thick is used to conduct electricity in bands around the inside edge of the bowl. The uppermost band is attached 1 inch from the rim of the bowl, a second band 1/16 inch below the first and a third the same distance below the second band. If larger insects are to be trapped, the gap between the middle and bottom bands should be increased to $\frac{1}{8}$ inch. A hole is bored in each band through the plastic bowl to take the electrical terminals in the form of a nut and bolt for each terminal, a bridge being fitted between the top and bottom terminals. Ramps are fitted (Fig. 1) to the sides of the bowl as required at an angle of about $30^{\circ}$ to the horizontal.

\section{The bait}

A number of known cockroach attractants including cinnamon, brown ale and powdered leather were compared. In all cases the most successful bait was one combining 


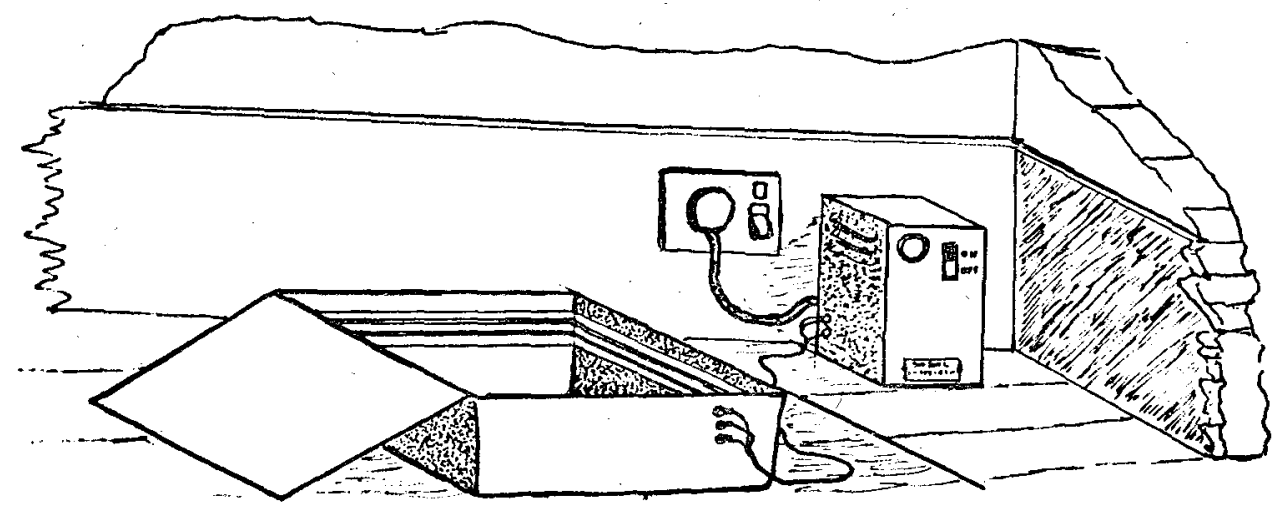

Fig. 1. The trap.

carbohydrate and fluid, thus the most readily available sources, bread and water, were used. Slices of white bread were placed in water in the two halves of a Petri dish in the bottom of the trap.

\section{The electrical supply}

The optimum voltage range is 12 to 25 volts. The electrical shock given to the user by 25 volts is only perceptible if the copper bands are touched with wet hands, and a higher voltage is unnecessary for the trapping of the insect. Below 12 volts the shock given to the insect is insufficient to prevent it from crossing the bands. The voltage is provided as direct current from a battery, or through a transformer from the mains supply (Fig. 2).

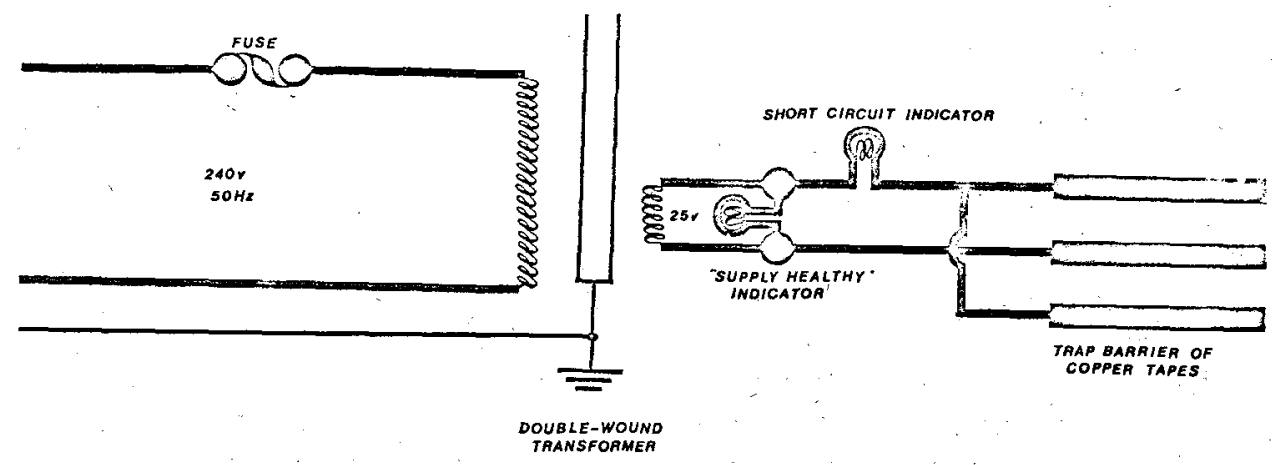

Fig. 2. The electrical circuit.

As can be seen the circuit incorporates "short circuit" and "supply healthy" indicator lamps. One lead from the transformer or battery is taken to the top band, bridged with the bottom band, and the other lead supplies the middle band. In crossing the banded area, the insect conducts the voltage from one band to the other through itself. The shock is sufficient to paralyse the creature temporarily, when it will typically lose its hold and fall back into the bowl. 
Disposal of the catch

Each week, or as often as is practical, the insects are killed and the bin emptied. The most satisfactory method used is to pour dilute alcohol or methylated spirit into the bowl with the current still flowing through the copper bands. The insects can be brushed off the edges of the bowl and will soon become paralysed in the fluid. The current can then be switched off, the alcohol drained away and the insects destroyed.

\section{Results}

The above equipment was tested for a period of 12 months in a hospital canteen which was initially very highly infested with the German cockroach Blattella germanica. The trap was set on the floor in a corner and left in the same position throughout the test period. The catch was emptied and counted each week and the trap reset with fresh bread and water. Weekly totals are shown in Figure 3. A further test was made in a

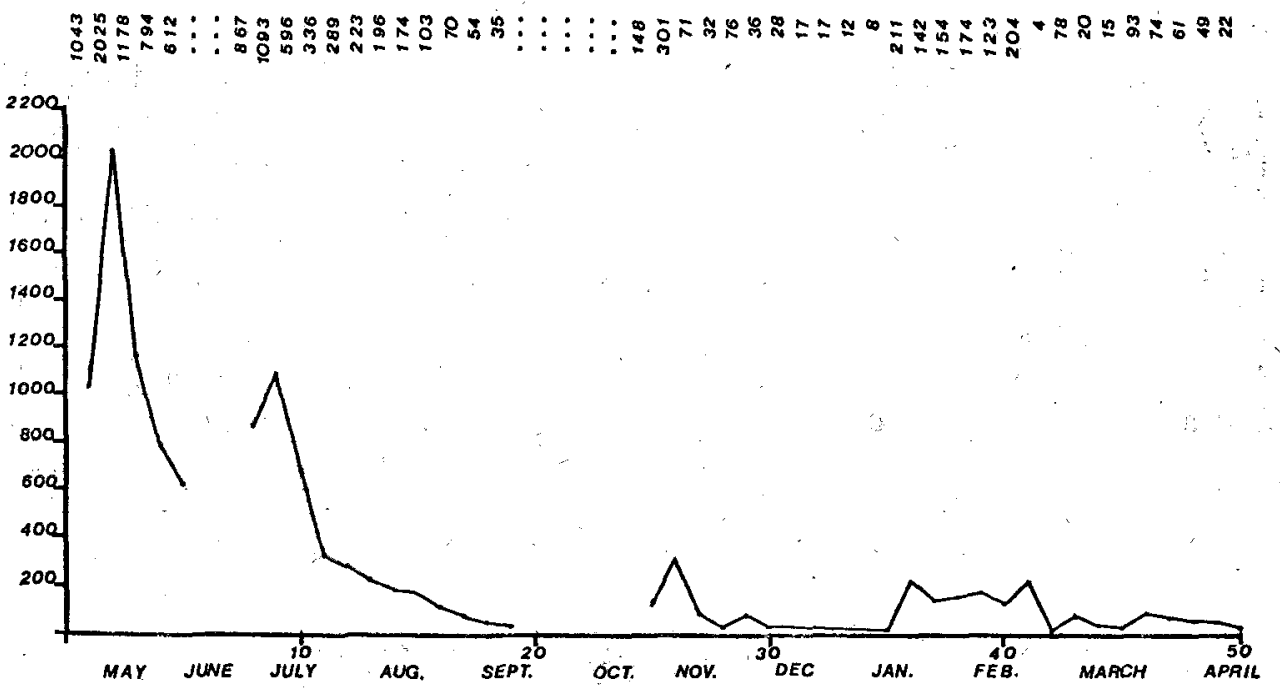

Fig. 3. Record of weekly catches of Blattella germanica.

cellar infested with the Oriental cockroach Blatta orientalis when 47 insects were trapped in 7 days.

Plastic dustbins equipped in the same manner as the traps, but without ramps, have been highly successful in containing laboratory colonies of Blattella germanica, Blatta orientalis and Periplaneta americana in a teaching insectary over the last 4 years.

\section{Discussion}

The effectiveness of this trap in controlling an infestation of Blattella germanica has been demonstrated conclusively, some 12,000 insects having been destroyed over a period of 12 months. Its success in complete eradication is dubious, but there can be few insecticide campaigns where complete long-term eradication has been achieved. 